\title{
COMPARISON OF EFFICACY OF PERIBULBAR BLOCK WITH THE COMBINATION OF 2\% LIDOCAINE AND 0.75\% ROPIVACAINE IN COMPARISON WITH 2\% LIDOCAINE AND 0.5\% BUPIVACAINE FOR CATARACT SURGERIES
}

\author{
V. Gnana Ganesh ${ }^{1}$, K. R. Padmanabhan², S. Ramadevi ${ }^{3}$
}

${ }^{1}$ Assistant Professor, Department of Anaesthesiology, Chengalpattu Medical College, Tamilnadu. ${ }^{2}$ Assistant Professor, Department of Anaesthesiology, Chengalpattu Medical College, Tamilnadu. ${ }_{3}^{3}$ Assistant Professor, Department of Anaesthesiology, Chengalpattu Medical College, Tamilnadu.

\section{ABSTRACT}

\section{BACKGROUND}

Most of the surgeries within the orbit, particularly cataract surgeries are done under regional anaesthesia in day-care surgical centres. Proper selection of patients, thorough pre-operative evaluation and preparation, continuous monitoring during regional anaesthesia are necessary for safe outpatient surgery in the elderly.

We compared the efficacy of peribulbar block in cataract surgery using the combination of $1: 1$ mixture of $2 \%$ lignocaine and $0.75 \%$ ropivacaine with $1: 1$ mixture of $2 \%$ lignocaine and $0.5 \%$ bupivacaine regarding the time required for onset of surgical anaesthesia and quality of postoperative analgesia.

\section{MATERIALS AND METHODS}

Sixty patients of either sex of ASA grade I and II between the ages of 50 to 70 years were randomly divided into two groups of thirty each. Group R received 1:1 mixture of $2 \%$ lignocaine with $0.75 \%$ ropivacaine, while group B received $1: 1$ mixture of $2 \%$ lignocaine with $0.5 \%$ bupivacaine along with $50 \mathrm{IU} / \mathrm{mL}$ of hyaluronidase and adrenaline 1 in 4,00,000. The final volume of the injected solution is $10 \mathrm{~mL}$ in both the groups.

\section{STATISTICAL ANALYSIS}

Continuous variables are presented as mean $\pm \mathrm{SD}$, ordinal and nominal data are presented as number and percentage. Comparison between these groups were made using student's ' $t$ ' test for quantitative data and Pearson's chi square test for qualitative data. Onset of sensory block, onset of motor block (minutes) and duration of analgesia were analysed using Student's ' $t$ ' test. A value of $\mathrm{P}<0.05$ was considered as significant.

\section{RESULTS}

The onset of sensory blockade was similar between the two groups, whereas the onset of motor blockade was delayed and duration of analgesia lasted longer in the ropivacaine group.

\section{CONCLUSION}

We concluded that the combination of $2 \%$ lidocaine with $0.75 \%$ ropivacaine is better for prolonged post-operative pain relief when compared with a combination of $2 \%$ lidocaine with $0.5 \%$ bupivacaine.

\section{KEYWORDS}

Peribulbar Block, Cataract Surgery Ropivacaine, Lidocaine, Bupivacaine.

HOW TO CITE THIS ARTICLE: Ganesh VG, Padmanabhan KR, Ramadevi S. Comparison of efficacy of peribulbar block with the combination of $2 \%$ lidocaine and $0.75 \%$ ropivacaine in comparison with $2 \%$ lidocaine and $0.5 \%$ bupivacaine for cataract surgeries. J. Evolution Med. Dent. Sci. 2016;5(82):6116-6120, DOI: 10.14260/jemds/2016/1381

\section{BACKGROUND}

Both peribulbar and retrobulbar blocks provide adequate anaesthesia for surgery on the cornea, anterior chamber and lens. Peribulbar block is considered preferable over retrobulbar block in achieving anaesthesia for intraocular and orbital surgeries. Hamilton and coworkers have shown that safe, comfortable and effective analgesia and akinesia of the eye can be obtained with peribulbar block. ${ }^{1}$

Financial or Other, Competing Interest: None.

Submission 22-09-2016, Peer Review 05-10-2016,

Acceptance 07-10-2016, Published 12-10-2016.

Corresponding Author:

Dr. V. Gnana Ganesh,

No. 45, Thiruvalluvar Street,

Vedhachalam Nagar,

Sevilimedu, Kancheepuram-631501.

E-mail: drgnanaganesh91@yahoo.com

DOI: $10.14260 /$ jemds $/ 2016 / 1381$

\section{(c) $($ ) $\$$}

Peribulbar block is easier and less painful to perform, has a higher margin of safety, equally effective without the need for accessory facial nerve block. Local anaesthetic solution is deposited within the orbit, but outside the muscle cone.

Kelman was first known to have performed this technique in 1970 (Unpublished). Davis and Mandel reviewed 16,225 peribulbar blocks and found them to be effective with a very low complication rate. ${ }^{2}$ Wong and Troll reviewed regional anaesthetic techniques for intraocular surgery and gave a good description of orbital anatomy. ${ }^{3,4}$ Kumar and Fanning discussed regional anaesthetic techniques including choice of anaesthetic mixture and types of needles. 5

\section{MATERIALS AND METHODS}

The study was carried out in the Department of Anaesthesiology after getting the Ethical Committee approval in association with the Department of Ophthalmology, Chengalpattu Medical College during the period between Jan 
2016 and April 2016. Sixty patients of either sex of ASA grade I and II between the ages of 50 to 70 years were randomly divided into two groups of thirty each.

\section{Inclusion Criteria}

- $\quad$ ASA 1 and 2.

- Age 60 to 70 years.

\section{Exclusion Criteria}

- $\quad$ ASA 3 and 4.

- Allergic to local anaesthetics.

- Patients on anticoagulants.

- Local sepsis.

- Orbital anomalies.

- Glaucoma.

\section{Group R}

Patients received $1: 1$ mixture of $2 \%$ lidocaine and $0.75 \%$ ropivacaine with $50 \mathrm{IU} / \mathrm{mL}$ of hyaluronidase and adrenaline 1 in $4,00,000$.

\section{Group B}

Patients received 1:1 mixture of $2 \%$ lidocaine and $0.5 \%$ bupivacaine with $50 \mathrm{IU} / \mathrm{mL}$ of hyaluronidase and adrenaline 1 in $4,00,000$.

The final volume of the injected solution is $10 \mathrm{~mL}$ in both the groups.

\section{Preoperative Preparation}

Basic investigations like $\mathrm{Hb} \%$, blood sugar and urea, serum creatinine, bleeding and clotting time, ECG and CXR were taken. Pre-op counselling regarding peribulbar block and surgery was given to all patients. Written consent was obtained and Visual Analog Scale (VAS) was explained to all the patients. The axial length of the eye was confirmed by ultrasound scan.

Patients were advised nil per oral for 6 hours prior to the procedure. Patients were premedicated with oral diazepam 5 mg, 2 hours before surgery.

Intravenous access with an 18G cannula was established before performing the block. ECG, non-invasive blood pressure and pulse oximetry of the patients were monitored.

\section{Procedure/Peribulbar Block}

Peribulbar block was performed as per Bloomberg's modification of the Davis and Mandel technique. ${ }^{6}$ It was done by an anaesthesia resident, not taking part in the further management of patients.

A 22-gauge, $25 \mathrm{~mm}$ needle was inserted in the inferotemporal region through the skin, at the junction of medial $2 / 3$ rd and lateral $1 / 3 r d$ of the lower orbital margin. Once the needle is under the globe, it is directed along the orbital floor up to the depth of the mid-orbit in the lateral extraconal space.

After careful negative aspiration, five millilitres of local anaesthetic was given. The second injection was given in the superonasal area by inserting the same needle through the upper eyelid vertically above the medial limbus to a depth of $2 \mathrm{~cm}$, aiming tangentially away from the globe in the medial extraconal space and another five millilitres of local anaesthetic was given. Addition of hyaluronidase improves penetration of the local anaesthetic drugs. ${ }^{7}$ Adrenaline decreases the absorption of local anaesthetics and prolongs the duration of action.

Fullness of the upper lid points to an increase in the orbital volume and correct site of injection; 10-20 minutes of intermittent ocular compression is applied after the injection.

Patients were assessed for sensory and motor block, quality of surgical anaesthesia and duration of analgesia.

Sensory block was evaluated by loss of sensation of the cornea with cotton at 2, 4, 6, 8 and 10 minutes after injection. Onset of sensory block was taken as the time from injection to loss of sensation.

Motor Block was evaluated in all the Four Quadrants using a 3-Point Scoring System

0 - Akinesia (ocular movement $<1 \mathrm{~mm}$ )

1 - Reduced movement (ocular movement 1-4 mm)

2 - Normal movement (ocular movement $>4 \mathrm{~mm}$ )

This scoring system gives a maximal aggregate score of 8 for the four muscles. A total score of $\leq 2$ or reduced movements in all direction was taken as an indication of successful block. Once successful block had been achieved, no further assessments were made.

\section{Quality of Surgical Anaesthesia was Graded as}

- Excellent - No pain at any time during surgery.

- Good - Minimal pain or discomfort.

- Poor - General anaesthesia had to be administered.

Intraoperatively, vital signs were recorded at regular intervals. Oxygen $4 \mathrm{~L} / \mathrm{min}$ was administered via the nasal cannula to all the patients under sterile drapes.

Assessment of pain in post-anaesthesia care unit using VAS was done every 15 minutes. Duration of effective analgesia was defined as time interval between peribulbar block and the time to reach VAS $\geq 3$. Once this score was reached, patients were given Tab. Ibuprofen $400 \mathrm{mg}$ and Tab. Paracetamol $500 \mathrm{mg}$ per orally as rescue analgesia.

\section{RESULTS}

Continuous variables are presented as mean $\pm \mathrm{SD}$, ordinal and nominal data are presented as number and percentage. Comparison between these groups were made using student's ' $\mathrm{t}$ ' test for quantitative data and Pearson's chi square test for qualitative data.

Onset of sensory block, onset of motor block (minutes) and duration of analgesia were analysed using student's ' $\mathrm{t}$ ' test. A value of $P<0.05$ was considered as significant.

\begin{tabular}{|c|c|c|c|c|}
\hline \multirow{2}{*}{$\begin{array}{c}\text { Time } \\
\text { (Minutes) }\end{array}$} & \multicolumn{2}{|c|}{ Group B } & \multicolumn{2}{c|}{ Group R } \\
\cline { 2 - 5 } & Frequency & $\%$ & Frequency & \% \\
\hline $0-2$ & 11 & 36.7 & 12 & 40.0 \\
\hline $3-4$ & 18 & 60.0 & 18 & 60.0 \\
\hline $5-6$ & 1 & 3.3 & 0 & 0.0 \\
\hline \multicolumn{2}{|c|}{ Table I: Onset of Sensory Block (Minutes) } \\
\hline
\end{tabular}




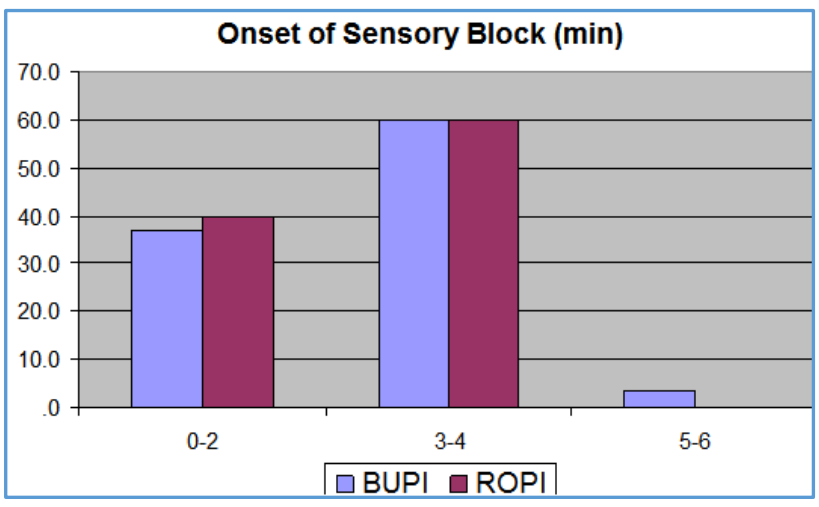

Fig. I

\begin{tabular}{|c|c|c|c|c|}
\hline \multirow{2}{*}{$\begin{array}{c}\text { Time } \\
\text { (Minutes) }\end{array}$} & \multicolumn{2}{|c|}{ Group B } & \multicolumn{2}{c|}{ Group R } \\
\cline { 2 - 5 } & Frequency & $\mathbf{\%}$ & Frequency & $\mathbf{\%}$ \\
\hline $3-4$ & 2 & 6.7 & 1 & 3.3 \\
\hline $5-6$ & 18 & 60.0 & 6 & 20.0 \\
\hline $7-8$ & 6 & 20.0 & 20 & 66.7 \\
\hline $9-10$ & 4 & 13.3 & 3 & 10.0 \\
\hline \multicolumn{3}{|c|}{ Table II: Onset of Motor Block (Minutes) } \\
\hline
\end{tabular}

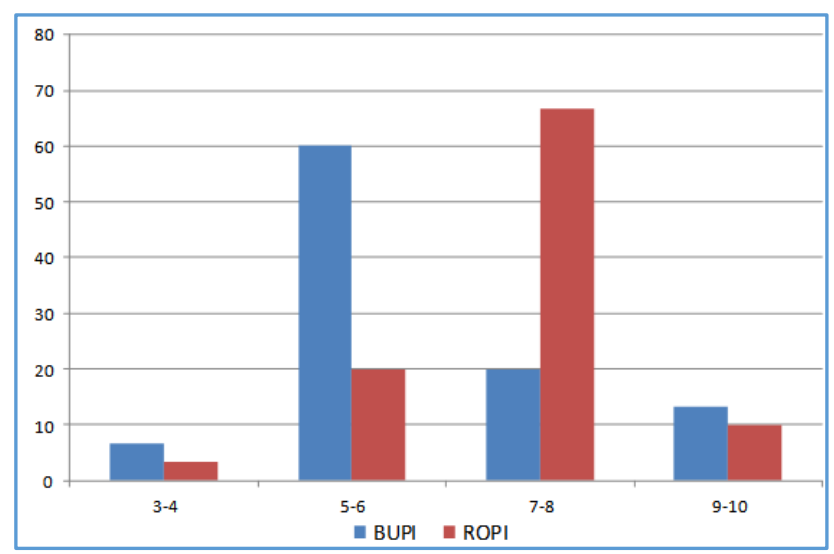

Fig. II: Onset of Motor Block (Min)

\begin{tabular}{|c|c|c|c|c|}
\hline \multirow{2}{*}{$\begin{array}{c}\text { Time } \\
\text { (Minutes) }\end{array}$} & \multicolumn{2}{|c|}{ Group B } & \multicolumn{2}{c|}{ Group R } \\
\cline { 2 - 5 } & Frequency & $\mathbf{\%}$ & Frequency & $\mathbf{\%}$ \\
\hline $121-240$ & 7 & 23.3 & 2 & 6.7 \\
\hline $241-360$ & 21 & 70.0 & 9 & 30.0 \\
\hline $361-480$ & 2 & 6.7 & 14 & 46.6 \\
\hline $481-600$ & 0 & 0.0 & 5 & 16.7 \\
\hline \multicolumn{6}{|c|}{ Table III: Duration of Analgesia (Minutes) } \\
\hline
\end{tabular}

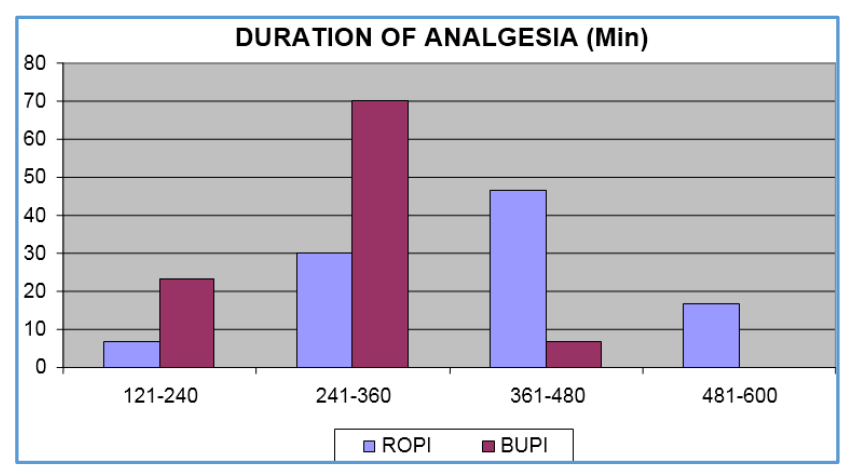

Fig. III

\begin{tabular}{|c|c|c|c|}
\hline Description & Bupivacaine & Ropivacaine & $\begin{array}{c}\text { P } \\
\text { value }\end{array}$ \\
\hline $\begin{array}{c}\text { Onset of Sensory } \\
\text { Block (minutes) }\end{array}$ & $2.70+.65$ & $2.63+.57$ & 0.671 \\
\hline $\begin{array}{c}\text { Onset of Motor } \\
\text { Block (minutes) }\end{array}$ & $6.53+1.81$ & $7.57+1.46$ & 0.018 \\
\hline $\begin{array}{c}\text { Duration of } \\
\text { Analgesia } \\
\text { (minutes) }\end{array}$ & $295.00+54.63$ & $414.67+99.47$ & 0.001 \\
\hline \multicolumn{4}{|c|}{ Table IV: P Value Comparison } \\
\hline
\end{tabular}

There was no statistically significant difference between the two study groups with regard to age, sex and weight. Mean time [SD] for the onset of sensory block was $2.70 \pm 6.5$ minutes in Group B and 2.63 \pm 0.57 minutes in Group R. Since the $p$ value is 0.671 , there is no significant difference in the onset of sensory blockade between both groups.

Mean time [SD] for the onset of motor block was $6.53 \pm 1.81$ minutes in Group B and $7.57 \pm 1.46$ minutes in Group R, whereas analgesia lasted for $295 \pm 54.63$ minutes in Group B and 414.67 \pm 99.47 in Group R. The p value for the onset of motor block and duration of analgesia were 0.018 and 0.001 , respectively. Since the p value is $<0.05$, there is a statistically significant difference among both the groups, with regard to onset of motor blockade and duration of analgesia.

\section{DISCUSSION}

The use of regional anaesthesia for ophthalmic surgery is associated with fewer respiratory and haemodynamic complications when compared to general anaesthesia. ${ }^{8}$ It also provides excellent postoperative analgesia. The incidence of postoperative nausea and vomiting is also less with regional anaesthesia. Nearly, $46 \%$ of people older than 75 years have vision problems related to cataract, requiring surgery. ${ }^{9}$ Regional anaesthesia is ideal due to increased frequency of intercurrent illness and multiple drug therapy in this age group. ${ }^{10}$

Retrobulbar anaesthesia is associated with rare but severe complications such as ocular perforation, direct optic nerve injury, extraocular muscle paresis, retrobulbar haemorrhage, retinal vascular occlusion and brainstem anaesthesia. 11

Davis and Mandel developed peribulbar block, which is associated with fewer complications than retrobulbar block. For this reason, peribulbar anaesthesia is now considered a safe and effective technique for cataract surgery. The disadvantages of peribulbar block over retrobulbar block include slower onset, more volume of local anaesthetic needed and less complete akinesia.

The onset of sensory block was $2.70 \pm 0.65$ minutes in Group B and $2.63 \pm 0.57$ minutes in Group R with a p value of 0.671 . Hence, there was no statistically significant difference between the two groups with regard to onset of sensory blockade.

This corresponds to study done by Luigi Gioia et al who compared $0.75 \%$ ropivacaine with a mixture of $2 \%$ lidocaine and $0.5 \%$ bupivacaine for vitreoretinal surgery. ${ }^{12}$ They concluded that $0.75 \%$ ropivacaine has an onset similar to that of the $2 \%$ lidocaine and $0.5 \%$ bupivacaine mixture and provides a better quality of postoperative analgesia. 
Huha $\mathrm{T}$ et al concluded that there were no clinically significant difference in the sensory blockade between $1 \%$ ropivacaine and $0.75 \%$ bupivacaine in peribulbar anaesthesia for cataract surgery. ${ }^{13}$

D. K. Woodward and A. T. S. Leung et al studied peribulbar anaesthesia with $1 \%$ ropivacaine and hyaluronidase $300 \mathrm{IU} \mathrm{mL}^{-1}$ : in comparison with $0.5 \%$ bupivacaine, $2 \%$ lidocaine and hyaluronidase $50 \mathrm{IU} / \mathrm{mL}$. They showed no difference in the rate of onset and degree of akinesia achieved.14

Regarding the onset of motor blockade, Group B (6.53 \pm 1.81 minutes) had a statistically significant rapid onset of motor blockade when compared to Group R $(7.57 \pm 1.46$ minutes) with $\mathrm{p}$ value of 0.018 . This corresponds to a study done by Perello A et al who concluded that there was a slower onset of akinesia in using ropivacaine alone. This could have been due to better motor blockade produced by $0.5 \%$ bupivacaine when compared to $0.75 \%$ ropivacaine, which produces more of sensory blockade. ${ }^{15}$

Didonato A et al compared efficacy of $0.5 \%$ levobupivacaine with $0.75 \%$ ropivacaine for peribulbar anaesthesia in cataract surgery. They showed that $0.5 \%$ levobupivacaine had early onset of sensory and motor blockade and better akinesia score than $0.75 \%$ ropivacaine. ${ }^{16}$ The duration of analgesia lasted for $295 \pm 54.63$ minutes in Group B and $414.67 \pm 47$ minutes in Group $R$ with a p value of 0.001 . The study showed highly statistically significant prolongation of duration of analgesia with Group R, which corresponds to the study done by Luigi Gioia et al, who compared $0.75 \%$ ropivacaine with a mixture of $2 \%$ lidocaine and $0.5 \%$ bupivacaine and concluded that the onset was similar in both the groups, while $0.75 \%$ ropivacaine provides a prolonged duration of postoperative analgesia.

Gillart $\mathrm{T}$ et al compared the effects of ropivacaine and bupivacaine, each combined with lidocaine, during peribulbar anaesthesia by single medial injection for cataract surgery. They concluded that lidocaine with ropivacaine produces better anaesthesia and similar analgesia when compared to lidocaine with bupivacaine. ${ }^{17}$

Corke PJ, Baker J, Cammack R, et al compared $1 \%$ ropivacaine and mixture of $2 \%$ lignocaine and $0.5 \%$ bupivacaine for peribulbar anaesthesia in cataract surgery. They concluded that both the groups had excellent surgical analgesia and akinesia. 18

One of the limitations of this study is the inclusion of $2 \%$ lignocaine in both the groups, which may influence the onset of sensory and motor blockade. Prolonged duration of analgesia in Group $\mathrm{R}$ could also be due to higher concentration of ropivacaine used, i.e. $0.75 \%$.

From our study, we found that the total duration of sensory blockade following peribulbar block is significantly prolonged with a combination of $2 \%$ lignocaine and $0.75 \%$ ropivacaine providing long lasting postop analgesia in patients undergoing cataract surgery.

\section{CONCLUSION}

From this prospective, randomised, double-blinded study, we found that the onset of sensory blockade was similar between the two study groups. But the onset of motor blockade was delayed and duration of analgesia lasted longer in the ropivacaine group. Hence, we concluded that the combination of $2 \%$ lidocaine with $0.75 \%$ ropivacaine is considered a better choice of local anaesthetic for prolonging postoperative pain relief when compared to a combination of $2 \%$ lidocaine with $0.5 \%$ bupivacaine.

\section{ACKNOWLEDGEMENTS}

We are very grateful to the Professors and Asst. Professors of Dept. of Ophthalmology. We also thank the Professors, Asst. Professors and Postgraduates of Dept. of Anaesthesiology. We are thankful to the Institutional Ethical Committee for their guidance and approval to the study. We thank all the patients who were subjected for this study. We also wish to state that no financial or material support obtained for this study.

\section{REFERENCES}

1. Hamilton RC, Gimbel HV, Strunin L. Regional anaesthesia for 12,000 cataract extraction and intraocular lens implantation procedures. Can J Anaesth 1988;35(6):61523.

2. Davis DB, Mandel MR. Efficacy and complication rate of 16,224 consecutive peribulbar blocks. A prospective, multicenter study. J Cataract Refract Surg 1994;20(3):327-37.

3. Wong DH. Regional anaesthesia for intraocular surgery. Can J Anaesth 1993;40(7):635-57.

4. Troll GF. Regional ophthalmic anaesthesia: safe techniques and avoidance of complications. J Clin Anaesth 1995;7(2):163-72.

5. Kumar CM, Fanning GL. Orbital regional anaesthesia. In Kumar CM, Dodds C, Fanning GL. (eds). Ophthalmic anaesthesia. Lisse, Netherlands, Swets \& Zeitlinger 2002:61-83.

6. Bloomberg LB. Administration of peribulbar anaesthesia. J Cataract Refract Surg 1986;12:677-9.

7. Dempsey GA, Barrett PJ, Kirby IJ. Hyaluronidase andperibulbar block. Br J Anaesth 1997;78(6):671-4.

8. Barker JP, Vafidis GC, Hall GM. Postoperative morbidity following cataract surgery. A comparison of local and general anaesthesia. Anaesthesia 1996;51(5):435-7.

9. Kahn HA, Leibowitz HM, Ganley JP, et al. The framingham eye study. Outline and major prevalence findings. Am J Epidemiol 1977;106(1):17-32.

10. Fisher SJ, Cunningham RD. The medical profile of cataract patients. Clin Geriatr Med 1985;1(2):339-44.

11. Hamilton RC. Complications of ophthalmic regional anaesthesia. In: Kumar CM, Dodds C, Fanning GL. (eds). Ophthalmic Anaesthesia. Lisse, Netherlands, Swets \& Zeitlinger 2002:181-96.

12. Gioia L, Prandi E, Codenotti $M$, et al. Peribulbaranesthesia with either $0.75 \%$ ropivacaine or $2 \%$ lidocaine and $0.5 \%$ bupivacaine mixture for vitreoretinal surgery: a double-blinded study. Anesth Analg 1999;89(3):739-42.

13. Huha T, Ala-Kokko TI, Salomaki T, et al. Clinical efficacy and pharmacokinetics of $1 \%$ ropivacaine and $0.75 \%$ bupivacaine in peribulbar anaesthesia for cataract surgery. Anaesthesia 1999;54(2):137-41.

14. Woodward DK, Leung AT, Tse MW, et al. Peribulbar anaesthesia with $1 \%$ ropivacaine and hyaluronidase $300 \mathrm{IU} \mathrm{ml}^{-1}$ in comparison with $0.5 \%$ bupivacaine, $2 \%$ lidocaine and hyaluronidase $50 \mathrm{IU} \mathrm{ml}^{-1}$. Br J Anaesth 2000;85(4):618-20. 
15. Perello A, George J, Skelton V, et al. A double-blinded randomized comparison of ropivacaine $0.5 \%$, bupivacaine $0.375 \%$-lidocaine $1 \%$ and ropivacaine $0.5 \%$-lidocaine $1 \%$ mixtures for cataract surgery. Anesthesia 2000;55(10):1003-7.

16. Di Donato A, Fontana C, Lancia F, et al. Efficacy and comparison of $0.5 \%$ levobupivacaine with $0.75 \%$ ropivacaine for peribulbar anaesthesia in cataract surgery. Eur J Anaesth 2006;23(6):487-90.
17. Gillart T, Barrau P, Bazin JE, et al. Lidocaine plus ropivacaine versus lidocaine plus bupivacaine for peribulbar anaesthesia by single medical injection. Anesth Analg 1999;89(5):1192-6.

18. Corke PJ, Baker J, Cammack R. Comparison of $1 \%$ ropivacaine and mixture of $2 \%$ lignocaine and $0.5 \%$ bupivacaine for peribulbar anaesthesia in cataract surgery. Anaesth Intens Care 1999;27(3):249-52. 